\title{
Creatinine Urine Excretion Rate
}

National Cancer Institute

\section{Source}

National Cancer Institute. Creatinine Urine Excretion Rate. NCI Thesaurus. Code

C117833.

A determination of the amount of creatinine being excreted in urine over a defined period of time. 